\title{
A Revolução Francesa em cena: o íntimo e o político em Ça Ira (1) Fin de Louis
}

The French Revolution on the scene: the intimate and the political in Ça Ira (1) Fin de Louis

Igor de Almeida Silva

Igor de Almeida Silva Professor do Departamento de Teoria da Arte e Expressão Artística na Universidade Federal de Pernambuco (UFPE)

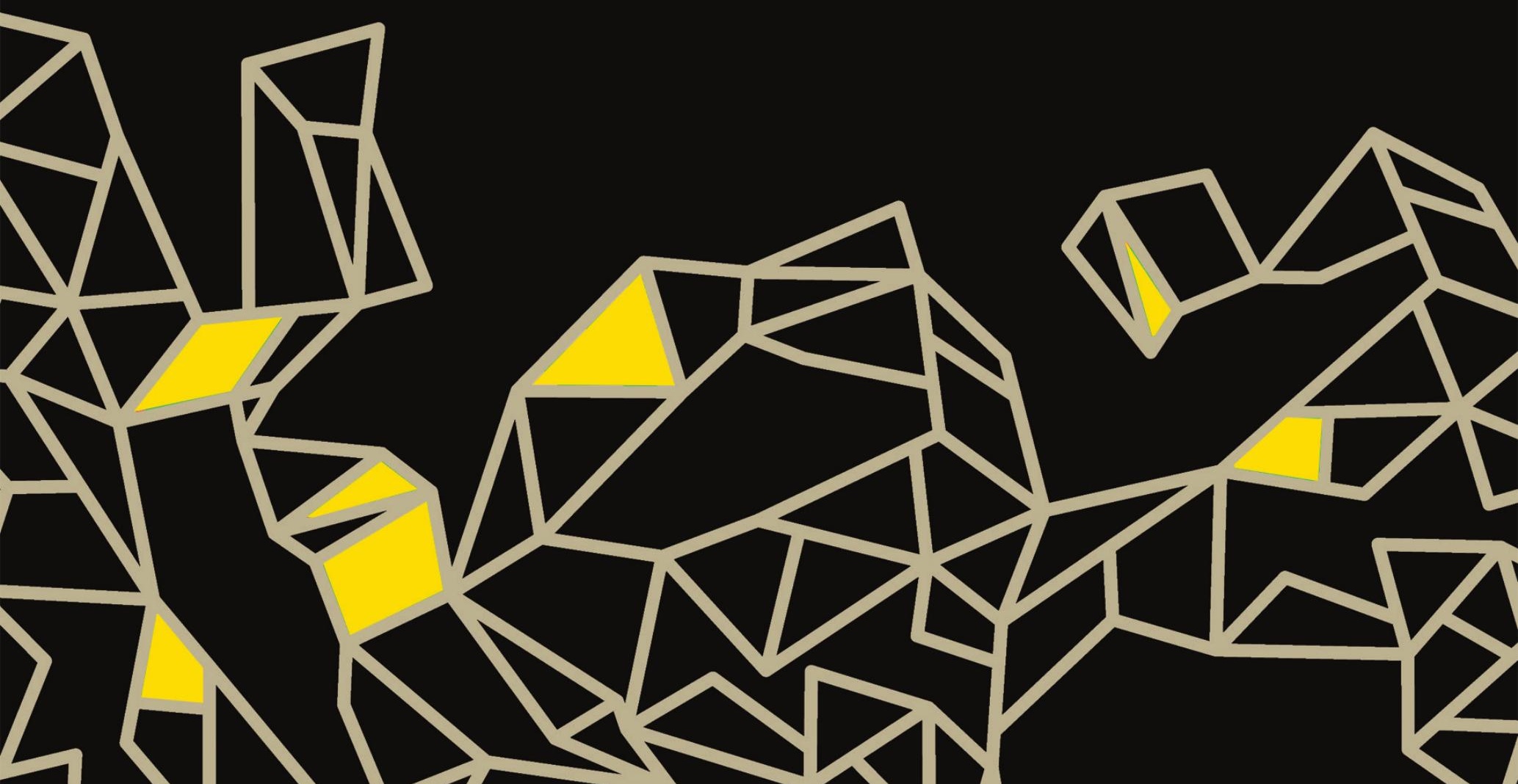




\section{Resumo}

Este ensaio apresenta um estudo do espetáculo Ça Ira (1) Fin de Louis, escrito e dirigido por Joël Pommerat. Inicialmente, busca-se estabelecer um diálogo entre Ça Ira e a histórica montagem de 1789, com direção de Ariane Mnouchkine. Em seguida, o espetáculo é examinado por meio de procedimentos recorrentes no trabalho de Pommerat, como, por exemplo, a neutralização do seu ponto de vista que expõe na peça situações, ideias e personagens sob diversas perspectivas. Por fim, este estudo baseia-se teoricamente no que Jean-Pierre Sarrazac chama de "teatros do íntimo" para observar a articulação entre o íntimo e o político em Ça Ira (1) Fin de Louis.

Palavras-chave: Revolução Francesa, Joël Pommerat, Teatro íntimo, Teatro político.

\section{Abstract}

This essay presents an analysis of the performance Ça Ira (1) Fin de Louis, written and directed by Joël Pommerat. Initially, it seeks to establish a dialogue between Ça Ira and the historic performance of 1789, directed by Ariane Mnouchkine. Then, the performance is examined through recurrent procedures in Pommerat's work, for example, the neutralization of his point of view exposing situations, ideas and characters from different perspectives in the play. Finally, this study is theoretically based on what Jean-Pierre Sarrazac calls "intimate theaters" to observe the articulation between the intimate and the political in Ça Ira (1) Fin de Louis.

Keywords: French Revolution, Joël Pommerat, Intimate theater, Political theater.

A Revolução Francesa é um período extremamente popular tanto do ponto de vista historiográfico quanto do da mitologia que se criou em torno dele. Trata-se de um mito moderno que inspira criadores das mais variadas expressões artísticas ao longo dos últimos dois séculos, seja na literatura e pintura, seja no cinema e teatro.

No âmbito do teatro, suas reescrituras dramáticas e cênicas constituem uma tradição que conecta passado e presente. A partir de obras como A morte de Danton (1835), de Georg Büchner; ou do ciclo de peças intitulado Teatro da 
Revolução, de Romain Rolland (escritas entre 1898 e 1938); ou ainda espetáculos como 1789, la révolution doit s'arrêter à la perfection du bonheur (1970) e 1793, la cité révolutionnaire est de ce monde (1972), de Ariane Mnouchkine com o Théâtre du Soleil, e Ça Ira (1) Fin de Louis (2015), de Joël Pommerat com a Compagnie Louis Brouillard, percebe-se uma tentativa de meditação do presente através do passado. Diante de situações gerais de crise, tanto política quanto econômica, e de transformações sociais, o mito da Revolução Francesa é sempre evocado. Como se o encontro em direção ao passado retomasse, de certa maneira, alguns aspectos da teoria benjaminiana de história, na qual o filósofo afirma que "Articular historicamente o passado não significa conhecê-lo 'como ele de fato foi'. Significa apropriar-se de uma reminiscência, tal como ela relampeja no momento de um perigo" (BENJAMIN, 1994, p. 224).

$E$, no panorama teatral francês, essa tradição da revolução posta em cena tem nos espetáculos do Théâtre du Soleil seus representantes mais emblemáticos. Por tudo isso, diante do sucesso internacional de Ça Ira (1) Fin de Louis, a referência aos espetáculos do Soleil é frequentemente mencionada pela crítica e imprensa especializada, como se Pommerat escrevesse um novo capítulo na história do teatro por intermédio desse espetáculo.

A trajetória de Joël Pommerat e seu grupo teatral apresenta similaridades ao trabalho do Soleil. Ambos têm no ator a essência e a força dos seus processos criativos, nos quais a improvisação, o trabalho colaborativo, o texto elaborado em paralelo ao espetáculo são elementos em comum. Inclusive alguns dos membros da Compagnie Louis Brouillard são antigos integrantes do Théâtre du Soleil. As similaridades também não cessam em relação a 1789 e Ça Ira: ambos partem de uma dramaturgia documental, consultando estudos e arquivos no processo de criação com os atores e demais membros da equipe artística.

Porém, mesmo compartilhando princípios de trabalho semelhantes, ambos espetáculos apresentam características bem distintas, como se fossem contrapontos um do outro: 1789 parte de uma perspectiva metateatral em que artistas de teatro de feira contam e representam a revolução para o povo, além de tomar uma posição ideológica bastante precisa, na qual se procura mostrar como a burguesia confiscou a revolução da população (PICON-VALLIN, 2014; DORT, 1979). Pommerat, por outro lado, tem como objetivo mostrar na peça 
"o nascimento da palavra política" (BOUCHERON; MAZEAU; WAHNICH, 2017, p. 17), sem um direcionamento ideológico, nem uma mensagem ou referência explícita a situações e personagens da Revolução Francesa ou da atualidade política. Seu objetivo é escrever sobre as ideologias: "uma história das ideias políticas e econômicas a fim de revelar filiações entre o passado e o hoje" (BOUDIER, 2017, p. 9, tradução nossa) ${ }^{1}$.

Para tanto, Ça Ira (1) Fin de Louis baseia-se na sequência histórica da assembleia dos notáveis (membros do primeiro e segundo estado), na qual o primeiro-ministro apoiado pelo rei tenta implementar uma reforma fiscal no país até a primavera de 1791, com o rei já sitiado em Paris e às vésperas da fuga da família real. De modo sutil, o espetáculo tem como eixo a figura do rei, cujos atos são determinantes para deflagrar os principais acontecimentos que originam e orientam os rumos da revolução. É sua figura reticente e silenciosa (e ao mesmo tempo amada pelo povo) - interpretado pelo ator Yvain Juillard - que atravessa todo o espetáculo, tornando-se um dos eixos da encenação.

Apesar de tomar como referência estudos recentes sobre o tema e, principalmente, um trabalho de pesquisa em arquivos (cartas, diários, memórias, arquivos parlamentares etc.) para alimentar as improvisações dos atores (assim como a criação dos demais artistas e profissionais envolvidos e a própria escritura do espetáculo), a revolução é aqui apresentada de modo incerto, isto é, sem uma reconstituição histórica direta. Em verdade a revolução é evocada, mas não nomeada. O único personagem identificado é o rei Luís $\mathrm{XVI}$, como se pode constatar no próprio título do espetáculo. Os demais personagens, nobres, políticos, revolucionários, homens do povo, possuem nomes ficcionais, sem fazer referência a nenhuma figura histórica, como Robespierre, Danton, Saint-Just, entre outros. Como diz Marion Boudier: "Nós não fazemos uma reconstituição da Revolução Francesa, mas sobretudo uma espécie de 'ficção verdadeira', que mistura elementos históricos e elementos ficcionais a fim de atualizar o passado, de torná-lo presente" (apud POIRSON, 2015, p. 654 , tradução nossa) ${ }^{2}$.

1 No original: "une histoire des idées politiques et économiques afin de révéler des filiations entre le passé et aujourd'hui".

2 No original: "Nous ne faisons pas une reconstituition de la Révolution Française, mais plutôt une sorte de 'fiction vraie', qui mêle des éléments historiques et des éléments fictifs afin d'actualiser le passé, de le rendre présent". 
Em Ça Ira, toda a sala é espaço de representação. Não apenas a presença das Forças Vivas e do elenco com suas intervenções na plateia confere esse sentido, mas a própria organização do espetáculo pressupõe uma cena imersiva, que incorpora o espectador sem, entretanto, requerer uma participação ativa em cena. Isso se deve ao fato de quase a totalidade do espetáculo ser constituída de discursos políticos, cenas de tribuna, nas quais os atores dirigem-se diretamente ao público, que é tomado então como testemunha, ou melhor, é incorporado aos debates representados, tornando-se membro da Assembleia Nacional ou de associações e clubes políticos de bairro. Pommerat chama de "Forças Vivas" o núcleo de amadores do teatro, cidadãos recrutados nas cidades por onde excursionam e que participam de cenas na plateia ou de composições e figurações no palco, cuja principal função é reforçar os elos entre encenação e público.

Segundo a dramaturgista Marion Boudier (2015, p. 146, tradução nossa):

Esta imersão física através do transbordamento da cena na sala sublinha indiretamente que não se pode abordar no teatro a questão da representação democrática sem interrogar a representação teatral ela mesma e a convenção que separa aqueles que olham daqueles que representam em ação ${ }^{3}$.

Em outras palavras: aqueles que agem e aqueles que olham, aqueles que fazem a política e aqueles que a seguem.

No entanto, em Ça Ira, como já dito, não há a defesa (pelo menos explícita) de nenhum personagem, partido, ideologia, ou ponto de vista histórico acerca da Revolução Francesa. Pommerat procura suspender seu ponto de vista para abordar contextos e personagens sob todos os ângulos possíveis. Uma tentativa de "grau zero" da escrita cênica que implica em uma suspensão de julgamento na qual cada personagem e situação cênica são apresentados em perspectivas opostas. Esse fato é perceptível tanto no nível da fábula da peça, à medida que os deputados da Assembleia Nacional vão mudando seu discurso e atitude - como o conservador Gigard (David Sighicelli), o moderado Carray (Éric

3 No original: "Cette immersion physique à travers le débordement de la scène dans la salle souligne indirectement qu'on ne peut aborder au théâtre la question de la représentation démocratique sans interroger la représentation théâtrale elle-même et la convention qui sépare ceux qui regardent de ceux qui représentent en action". 
Feldman) e o radical Possion-Laville (Yvain Juillard) -, ou quando assumem posições no limite do razoável, a exemplo da deputada radical Lefranc (Saadia Bentaïeb) que defende a violência e os assassinatos cometidos pelo povo como ações imaculadas acima de qualquer julgamento; quanto no nível da estrutura da encenação, permeada pelo gosto do paradoxo e do oximoro.

Para começar podemos tomar o espaço em seu vazio monumental, em sua exuberante sobriedade, como exemplo. No palco, gigantescos biombos que mudam suas posições no suceder de novas cenas, criando uma variedade de espaços ficcionais amparados pela luz e complementados por apenas alguns elementos: mesas e cadeiras predominantemente. Essa amplitude da cena contrasta com a presença do ator, com o seu jogo de constante troca de papéis e centrado na palavra, no discurso político que toma de assalto o homem comum.

Visando uma "contemporaneidade atemporal", ao mesmo tempo próxima e distante, os figurinos e adereços ganham importância fundamental ao caracterizar os atores em uma visualidade retrô, em torno dos anos 1960 e 1970. No entanto, essa caracterização passa longe do clichê, já que o espetáculo se pretende um jogo entre realidade e ficção. A figurinista Isabelle Deffin carrega os figurinos de um peso, de um desgaste natural pelo uso, mesmo no caso de personagens representantes da nobreza. Esse efeito de real dos figurinos contrasta com o teatralismo de certos adereços, como o uso abundante de perucas que pontua o contínuo jogo (troca) de papéis dos atores. Essa espécie de "jogo de perucas" Ihe confere certo artificialismo e prazer lúdico, contrastando com o predominante verismo e a sobriedade do espetáculo como um todo. São figuras inseridas no real, mas carregadas de teatralidade.

Muitos atores assumem vários personagens, frequentemente em lados opostos no que tange aos aspectos sociais e ideológicos: Agnès Berthon, por exemplo, representa a irmã do rei (Elisabeth), uma aristocrata reacionária partidária da contrarrevolução (Versan de Faillie) e uma ultrarradical das assembleias de bairro em Paris (Marie Sotto); Ruth Olaizola é a deputada conservadora Hersch e um membro do comitê de bairro que se radicaliza progressivamente em prol da luta armada; Yannick Choirat faz o primeiro-ministro, responsável pela tentativa de reforma fiscal que garantiria a igualdade de impostos, e o deputado conservador Cabri; Yvain Juillard representa o rei e também o deputado radical Possion-Laville, responsável pela proposição da 
redação da Declaração dos Direitos do Homem e do Cidadão; Anne Rotger faz a rainha, a deputada conservadora Camus e uma mulher que participa das assembleias de bairro; Simon Verjans é o deputado conservador aristocrata Lacanaux e também o deputado radical Boberlé; Bogdan Zamfir também se alterna entre um deputado conservador vindo da aristocracia (Marbis) e um ultrarradical das assembleias de bairro (Kristophe Hémé).

Essa superposição de personagens para um mesmo ator, tão diversos nas ideias que representam, configura-se como procedimento capaz de reforçar a suspensão do ponto de vista do autor-encenador, por impedir que os atores (pelo menos sua maioria) sejam associados pelo espectador a determinados personagens ou ideologias ao longo do espetáculo. Essa neutralização de perspectiva estimula a percepção e a interpretação do espectador, justamente por procurar escapar da lição política. Por meio da presença e do corpo do ator, mostra-se que uma situação ou personagem possui sempre o seu contrário.

Outro aspecto importante do espetáculo é o espaço: boa parte da peça se passa em lugares públicos destinados à discussão política: Salão dos Deputados do Terceiro Estado, Assembleia Nacional, assembleias de bairros. Há evidentemente cenas em espaços íntimos, situadas no palácio, apresentando o rei e sua corte. Encontramos aqui o político e o íntimo, a casa e o mundo. Essa é uma sutil equação que se faz presente em Ça Ira (1) Fin de Louis. Para Jean-Pierre Sarrazac, o íntimo é o contrário do secreto, seu destino é voltar-se ao exterior e oferecer-se enquanto espetáculo ao olhar do outro: "O íntimo não poderia [...] ser sistematicamente posto em oposição ao espetacular. Porque o íntimo não é, na verdade, nada mais que uma profundidade fingida, um sutil efeito de superfície" (SARRAZAC, 2013, p. 22). Baseando-se, sobretudo, nas dramaturgias de Strindberg, Maeterlinck e Tchékhov e no pensamento de Diderot, Sarrazac busca as bases desses teatros do íntimo. Para ele, o "teatro íntimo supõe a conflagração entre o pequeno e o grande, o microcosmo e o macrocosmo, a casa e o universo, o eu e o mundo" (lbid., p. 24). É Diderot quem "desenha para os séculos vindouros o novo perímetro do teatro: nesse círculo se inscreve um triângulo cujos vértices se chamam eu, a casa e o mundo e que delimita a área de todo o teatro do íntimo" (Ibid., p. 26).

O espaço do político (o espaço público por excelência, mas sobretudo a grande assembleia, ou o mundo, segundo Sarrazac) é reservado 
prioritariamente ao homem comum que passa a ocupá-lo a partir da revolução, enquanto o espaço do íntimo - a casa - é mostrado principalmente nos palácios de Versalhes e do Louvre, onde o rei se encontra não apenas tomado pelas questões de Estado, mas também pelos problemas de ordem familiar: a morte do filho, as intromissões e palpites da irmã e da esposa que apenas o atrapalham nas questões políticas. Ou seja, o ambiente aristocrático anunciando o ambiente da família burguesa. Se às vésperas da revolução o mundo é um inferno, a casa é tão desesperante quanto, tornando-se um purgatório como a casa tchekhoviana. Assim como os personagens de Tchékhov, Luís $\mathrm{XVI}$ se aborrece em casa. Além disso, seu mutismo desconcertante expõe seu espaço interior, como no teatro íntimo de Strindberg, que "parte do silêncio e, depois do breve intervalo de representação [...], volta ao silêncio" (Ibid., p. 22).

Mas em nenhum desses espaços, público e privado, os personagens estão protegidos. São espaços de conflitos, dúvidas, fraquezas, reticências e transformações. Todos falam apenas de política. Todos discursam. São tomados pela história e, subitamente, se veem impelidos a tomar decisões por si mesmos e pelos outros. Como diz Jacques Rancière, "a política não são os grupos que se exprimem através de representantes, mas são de antemão pessoas que decidem que eles ocupam esta posição de sujeito, que eles sejam operários, proletários, mulheres..." (2013, p. 9, tradução nossa)4. Essa parece ser uma das principais questões da peça, que atualmente ecoa tanto na Europa quanto no Brasil e em outras partes do mundo, ao colocar todos os personagens como agentes políticos. Pessoas comuns - muitas vezes apenas preocupadas com a concorrência desleal dos doces feitos pelas freiras com isenção de impostos do que com questões "mais filosóficas", como a liberdade e os direitos do homem, como fala uma mulher artesã confeiteira em uma reunião de bairro -, mas que são impelidas, subitamente, a se organizar democraticamente, sem estarem preparadas ou desejarem isso, partilhando uma mesma trajetória de aprendizagem. Todos são homens comuns na casa ou no mundo. E, ao mesmo tempo, são homens políticos. De modo dialético, o espetáculo se estrutura entre o íntimo e o político, a casa e o mundo. Talvez seja essa uma

4 No original: "la politique, ce ne sont pas des groupes qui s'expriment à travers des représentants, mais ce sont d'abord des gens qui décident qu'ils occupent cette position de sujet, qu'ils sont les ouvriers, les prolétaires, les femmes..." 
das principais diferenças e contribuições de Ça Ira e Joël Pommerat na série de representações da Revolução Francesa no teatro, tornando esse período da história da França ao mesmo tempo próximo e distante de nossa sensibilidade e percepção.

\section{Referências bibliográficas}

BENJAMIN, W. Sobre o conceito de história. In: Magia e técnica, arte e polí-

tica: ensaios sobre literatura e história da cultura. Tradução Sérgio Paulo Rouanet. 7. ed. São Paulo: Brasiliense, 1994. p. 222-232.

BOUCHERON, P.; MAZEAU, G.; WAHNICH, S. Usages de l'histoire, fétiches de la

Révolution. Retour sur Ça Ira (1) Fin de Louis de Joël Pommerat. Thaêtre [en ligne], Paris, p. 1-41, mis en ligne le 9 juin 2017. Chantier \#2: La Révolution selon Pommerat. Disponível em: <https://goo.gl/EtDA64>. Acesso em: 28 maio 2018. BOUDIER, M. Avec Pommerat: um monde complexe. Arles: Actes Sud-Papiers, 2015.

. La dramaturgie comme recherche : écrire avec la scène (de l'histoire). Retour sur le processus de création de Ça Ira (1) Fin de Louis. Thaêtre [en ligne], Paris, p. 1-80, mis en ligne le 9 juin 2017. Chantier \#2: La Révolution selon Pommerat. Disponível em: <https://goo.gl/6AJpHs>. Acesso em: 28 maio 2018.

DORT, B. À L'heure du Soleil. In: Théâtre en jeu: essais de critique 19701978. Paris: Éditions du Seuil, 1979. p. 64-78.

PICON-VALLIN, B. Le Théâtre du Soleil: les cinquante premières années. Arles: Actes Sud-Papiers, 2014.

POIRSON, M. Le totem de notre modernité politique. Conversation sur la genèse du spectacle Ça Ira (1) Fin de Louis, avec Saadia Bentaïeb, Marion Boudier, Isabelle Deffin, Guillaume Mazeau, Bogdan Zamfir. Revue d'Histoire du Théâtre, Paris, n. 268, p. 647-662, 2015. Dossier Révolution(s) en actes.

POMMERAT, J. Ça Ira (1) Fin de Louis. Arles: Actes Sud-Papiers, 2016.

RANCIÈRE, J. Les Scènes de l'émancipation. Entretien avec Armelle Talbot et Olivier Neveux au 28 mars 2012. Théâtre/Public, Gennevilliers, n. 208, p. 8-15, avril/juin 2013. Dossier Penser le spectateur.

SARRAZAC, J.-P. O íntimo e o cósmico: teatro do eu, teatro do mundo (do naturalismo ao teatro do cotidiano). In: Sobre a fábula e o desvio. Organização e tradução por Fátima Saadi. Rio de Janeiro: Teatro do Pequeno Gesto; 7Letras, 2013. p. 17-70.

Recebido em 25/10/2017

Aprovado em 09/05/2018

Publicado em 29/06/2018 